f. med. Genet. (1965). 2, 26.

\title{
Monozygotic Twinning in Mice
}

\author{
M. E. WALLACE and D. A. WILLIAMS \\ From the Department of Genetics, and the Statistical Laboratory, University of Cambridge
}

Because of the predominance of multiple ovulation in mice, it has been generally accepted that evidence for monozygotic twinning would be difficult to obtain. The two attempts that have been made have failed to find any evidence for twins surviving birth at a measurable rate. In Fisher and Mather's (1936) sevenfold backcross experiment there is no evidence of twinning at all. In each of Bateman's (1960) two cases of uniovular twinning (found by dissection) one twin is so placed that it is unlikely to survive until birth.

The possibility of other kinds of monozygotic twinning, and that their frequency varies from stock to stock, remains open. The present paper gives an account of one stock in which the evidence indicates a twinning rate, measured at 3 weeks of age, of about $I$ in 100 births.

\section{Design}

In man, the evidence that any one pair of twins is identical rather than fraternal rests essentially upon the remoteness of the chance that for every measurable factor for which any two members of the population may in general be expected to differ, the two under study do not differ. Factors chosen for measurement are, then, preferably known to segregate widely in the population, and the chance of identity for all factors is essentially the product of the chance of identity for each. (See, for example, Smith and Penrose, 1955; Shields, 1962.) There are, of course, further refinements, but this simple concept is clearly applicable to other species than man.

Stevens' treatment (1937) of Fisher's sevenfold backcross shows that this concept may be used to design an experiment in mice whose results may be similarly and as simply analysed as are those for human twins. If $f$ independent factors are made to segregate simultaneously in backcross or 'testcross' fashion, the chance that any one pair of the progeny

Received July 15, 1964. will be identical for one factor is $\frac{1}{2}$, and for $f$ factors is the product of the chances for each factor, i.e 3 $\left(\frac{1}{2}\right)^{p}$. For $f$ factors there are $n=2^{f}$ possible classes $\stackrel{0}{\sim}$ so that the number of identical pairs expected forlitter size $\mathrm{s}$ is as follows (Stevens (1937), $\$ 2$ and $\$ 4$ )

$$
\mathrm{E}_{\mathrm{sf}}=\mathrm{s}-\mathrm{n}+\mathrm{n}\left(\mathrm{I}-\frac{\mathrm{I}}{\mathrm{n}}\right)^{\mathrm{s}}
$$

with variance $\mathrm{V}_{\mathbf{s} f}=$

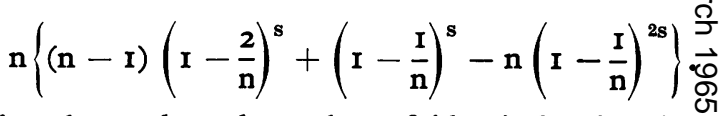

An observed total number of identical pairs significantly exceeding the expected number, aso obtained by calculation for all values of $s$ and $n,-$ clearly indicates the existence of pairs identicalo from causes other than chance.

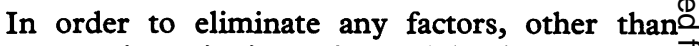
monozygotic twinning, that might increase the $\overrightarrow{0}$ expectation of identical pairs and its variance, cor-3 rections have to be made to the above expressions for all segregational irregularities which can make the $\mathrm{n}$ classes have unequal probabilities. These will be single-locus departures from $I: I$, two-locus inter -0. actions, i.e. departures from $I: I$ of parental versus non-parental combinations for pairs of loci, and, if they exist, deviations in respect of higher-order interactions.

It is important to notice that it is not necessary to be able to discern the causes of observed depar- $\rightarrow$ tures. Clearly, differential viability and imperfect? penetrance are the likeliest causes of departure $N$ from the single-locus expectation of $I: I$, and $\%$ linkage, interaction in terms of viability and pene- $N$ trance, and affinity are the likeliest causes of twolocus departure from I:I. Adjustment requires no을 knowledge of these or any other causes of depart-co

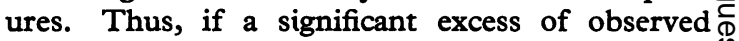
identical pairs over the adjusted expectation is $\stackrel{\oplus}{?}$ obtained, this excess cannot be ascribed to possible $T$ genetic phenomena as yet unknown. The excess pairs can only be genetically identical, i.e. monozygotic twins. 


\section{Material}

To maximize the sensitivity of the design, the calculable expectation of identical pairs and its variance must clearly be minimized. The experiment must therefore include as many factors as possible, and those must be chosen that are least likely to show single-locus disturbance and linkage, etc. Each must also affect, as far as possible, a different physiological aspect of the organism, so that all $2^{\mathrm{f}}$ classes are visually discrete, and-a practical consideration-so that the multiplymutant phenotypes to be used for breeding are, in fact, viable and fertile.

To this end, the experiment was carried out by one of us (M.E.W.) as follows. The four dominant mutants rex $(R e)$, brachyury $(T)$, naked $(N)$, and white $\left(M i^{\mathrm{wh}}\right)$ were combined into one panel; they were maintained heterozygously (by successive complementary matings) as all but rex are relatively inviable homozygously. Five recessive mutants pied $(s)$, brown $(b)$, shaker-I $(s h-I)$, shortear (se), and non-agouti (a) were combined into another panel and maintained homozygously. The linkage groups involved are respectively VII, IX, VI, XI, III, VIII, I, II, and V.

Crosses between the two panels produced $F_{1}$ heterozygous for all recessives and for various combinations of dominants. From among these, five- to ninefold heterozygotes of both sexes were backcrossed to the multiple recessives, so that the progeny segregated for up to ro independent factors simultaneously ( 9 mutants, and sex: linkage group $\mathrm{XX}$ ), producing $\mathbf{2}^{10}=\mathrm{I}, 024$ possible classes. The progeny were classified, the number of identical pairs scored, and the data examined for single-locus and two-locus deviations (Tables I, II, and III).

Further analyses were then carried out by one of us (D.A.W.) as follows. Higher-order interactions were examined and found to be small enough to make a negligible contribution to the corrections. Stevens' statistical treatment was enlarged to take account of the significant two-locus deviations. Computation was made of the expectations and variance adjusted according to these and the singlelocus deviations, and the twinning frequency was estimated (see under Analysis).

\section{Data}

Identical pairs are distributed as in Table I. There is a total of 9 in II 4 litters (i.e. in about 500 mice).

Single-locus ratios are given in Table II. Although the total $\chi^{2}$ is insignificant, and also the heterogeneity $\chi^{2}$, the significant deficiency of $N$ and $s$ should probably be considered real : in other experi- ments $N$ is often slightly inviable and $s$ slightly impenetrant.

Two-locus interactions give $\chi^{2}$ values as in Table III. Here again the total $\chi^{2}$ is barely significant, but the four individually significant values

\section{TABLE I}

DISTRIBUTION OF THE OBSERVED IDENTICAL PAIRS OF PHENOTYPES

\begin{tabular}{|c|c|c|c|c|c|c|c|c|c|c|c|}
\hline \multirow{2}{*}{$\begin{array}{c}\text { No. of } \\
\text { Factors, f, } \\
\text { Segregating }\end{array}$} & \multicolumn{10}{|c|}{ Litter Size, s } & \multirow{2}{*}{$\begin{array}{l}\text { Total } \\
\text { No. of } \\
\text { Litters }\end{array}$} \\
\hline & 2 & 3 & 4 & 5 & 6 & 7 & 8 & 9 & IO & II & \\
\hline $\begin{array}{r}6 \\
7 \\
8 \\
9 \\
10\end{array}$ & $\begin{array}{l}1 \\
1 \\
3 \\
6\end{array}$ & $\begin{array}{l}3 \\
9 \\
9\end{array}$ & $\begin{array}{c}\text { I } \\
3 \\
7 \\
\mathbf{I} \mathbf{1}\end{array}$ & $\begin{array}{l}2 \\
4 \\
8 \\
6\end{array}$ & $\begin{array}{l}1^{*} \\
2^{*} \\
6^{*} \\
5 \\
4^{*}\end{array}$ & $\begin{array}{l}1^{*} \\
2 \\
7^{*} \\
2^{*}\end{array}$ & $\begin{array}{l}I^{*} \\
2^{*} \\
2 \\
I\end{array}$ & I & $\mathbf{I}$ & $\mathbf{I}$ & $\begin{array}{r}3 \\
8 \\
21 \\
43 \\
39\end{array}$ \\
\hline $\begin{array}{c}\text { Total No. } \\
\text { litters }\end{array}$ & I I & $2 I$ & 22 & 20 & 18 & 12 & 7 & $\mathbf{I}$ & I & I & I I 4 \\
\hline
\end{tabular}

The figures in the table are the number of litters, of the size, and with the number of factors segregating, indicated by the margins. ${ }^{*} A$ star indicates that one of these litters contained one identical pair. Total number of identical pairs is thus 9 .

TABLE II

SINGLE LOCUS RATIOS

\begin{tabular}{|c|c|c|c|c|}
\hline & No. Mutant & No. Normal & Total & $x^{2}$ \\
\hline $\begin{array}{l}\text { Sex } \\
R e \\
T \\
N \\
M i \text { wb } \\
s \\
b \\
s h \mathrm{I} \\
s e \\
a\end{array}$ & $\begin{array}{l}284^{*} \\
208 \\
199 \\
181 \\
250 \\
223 \\
275 \\
231 \\
261 \\
251\end{array}$ & $\begin{array}{l}268^{*} \\
193 \\
203 \\
223 \\
286 \\
267 \\
277 \\
245 \\
286 \\
251\end{array}$ & $\begin{array}{l}552 \\
401 \\
402 \\
404 \\
536 \\
490 \\
552 \\
476 \\
553 \\
502\end{array}$ & $\begin{array}{l}0.46 \\
0.56 \\
0.04 \\
4.37 \dagger \\
2.42 \\
3.95 \dagger \\
0.07 \\
0.41 \\
0.76 \\
0.00\end{array}$ \\
\hline Total & 2,369 & 2,499 & 4,868 & $\begin{array}{r}13.04 \\
3.47\end{array}$ \\
\hline $\begin{array}{l}\text { Hetero- } \\
\text { geneity } \chi^{2}\end{array}$ & & & & $\begin{array}{l}9.57 \\
\text { for } 9 \mathrm{~d} . f .\end{array}$ \\
\hline
\end{tabular}

* 284 were male, 268 were female.

+ Significant at $5 \%$ level.

TABLE III

$\chi^{2}$ VALUES FOR TWO-LOCUS INTERACTIONS

\begin{tabular}{|c|c|c|c|c|c|c|c|c|c|}
\hline & Sex & $R e$ & $T$ & $N$ & $M i^{\text {wh }}$ & $s$ & $b$ & $s h-\mathrm{I}$ & se \\
\hline $\begin{array}{l}R e \\
T \\
N \\
M i \text { wh } \\
s \\
b \\
s h-I \\
s e \\
a\end{array}$ & $\begin{array}{l}0.64 \\
0.89 \\
0.56 \\
0.31 \\
2.22 \\
0.00 \\
1.88 \\
0.52 \\
0.16\end{array}$ & $\begin{array}{l}0.03 \\
2.91 \\
4.37 \\
0.42 \\
0.16 \\
1.92 \\
0.49 \\
0.00\end{array}$ & $\begin{array}{l}2.44 \\
0.01 \\
0.42 \\
0.12 \\
2.02 \\
0.30 \\
7.31_{+}^{+}\end{array}$ & $\begin{array}{l}0.58 \\
0.03 \\
6.19 \dagger \\
0.15 \\
0.42 \\
0.00\end{array}$ & $\begin{array}{l}0.93 \\
0.67 \\
0.14 \\
0.23 \\
0.35\end{array}$ & $\begin{array}{l}0.05 \\
0.02 \\
8.08 \pm \\
3.81\end{array}$ & $\begin{array}{l}3 \cdot 52 \\
2 \cdot 48 \\
1 \cdot 05\end{array}$ & $\begin{array}{l}2.57 \\
0.68\end{array}$ & 0.34 \\
\hline
\end{tabular}

* Significant at $5 \%$ level.

Significant at $\mathbf{2} \%$ level.

Total $\chi^{2}=62 \cdot 39$

Significant at I \% level. 
(for $s-s e, T-a, N-b$, and $R e-M i$ wh) should also be considered real. A discussion of the probable cause, affinity, will be given elsewhere.

\section{Analysis}

Details of the analysis are given in the Appendix. This shows that, with corrections for single-locus deviations and interactions between loci, the expectation of pairs identical by chance alone is $4 \cdot 18$, with standard deviation $2 \cdot 00$. The observation of 9 identical pairs gives a significant excess, with probability only $\mathrm{I} \cdot 52 \%$ Thus it may be concluded that about half the observed identical pairs were monozygotic. The estimated frequency of monozygotic births is $I$ in 100 , with $95 \%$ probability that the true frequency lies between 0.2 and 2.6 per 100 births.

It is worth noting here that if $n$ is very large, $E_{s f}$ and $V_{s f}$ approximate to $\frac{s(s-I)}{2 n}$, and that the numerous single-locus and two-locus deviations considered have produced only small corrections. This simple expression may therefore be used to calculate the approximate significance of any observed number of identical pairs, and in all but borderline cases it will be unnecessary to proceed with the more accurate calculatior.

By analogy with the calculation of expectation of number of identities (Stevens (1937), \$4) it can be shown that the sum of numbers of identical and complementary pairs is given by $s-\frac{n}{2}+\frac{n}{2}\left\{r-\frac{2}{n}\right\}^{s}$. If we use the convention that there can never be more than one complementary pair in a complementary class (e.g. if in a litter there is an identical pair and their common complement, this counts as one identical and one complementary pair), then the expected number of complementary pairs only is given by,

$\left\{s-\frac{n}{2}+\frac{n}{2}\left(I-\frac{2}{n}\right)^{s}\right\}-\left\{s-n+n\left(I-\frac{I}{n}\right)^{s}\right\}$.

When $\mathrm{n}$ is large this approximates to $\frac{s(s-r) \text {, which }}{2 n}$

equals the expected number of identities.

A simple guide to the progress of this type of experiment is thus merely to count the number of each kind of pair: if the observed number of complementary pairs does not exceed the observed number of identical pairs, the data are worth examining more closely.

\section{Discussion}

A high frequency of monozygotic twinning in the $\stackrel{\mathbb{P}}{+}$ mouse would clearly be of practical use in the $\overrightarrow{\vec{F}}$ experimental discrimination between genotypic and environmental causes of variation; in addition, $\frac{C}{0}$ their genetic identity would be more certain than $\bar{c}$ is that of members of an inbred line (Wallace, 1965). $\frac{\vec{\phi}}{\overrightarrow{0}}$

First, twins would have to be distinguished from $\propto$ pairs identical merely by chance. Sufficiently long के survival of skin grafts between members of pairs $\vec{\circ}$ would indicate identity for at least three further major loci as well as minor ones. Pairs can also $\vec{\omega}$ be tested for identity in blood constituents (at least? 5 loci) and in polygenically controlled systems such as the expression of the major loci already segre-i gating, the vertebral number (by radiograph), $\overrightarrow{-}$ endocrine, and other physiological variations- o urine constituents, etc. (see refs. in Wallace, 1965). 음 Since the parents of putative mouse twins can alsobe tested, it should become possible to calculate and 3 minimize the chance of including fraternals in a group of supposed monozygotics.

It would also be possible to increase the fre- $\vec{\theta}$ quency of monozygotic twins, if the tendency is or heritable. Comparison of the present data with Fisher's and with Green's (1934) indicates that this may be the case. The lack of evidence for twinning in Fisher's material indicates (despite the overlap between his upper fiducial limit of 7 per 1,000 and $\frac{}{\circ}$ our lower one of 2 per 1,000 ) that there is a real $\varrho$ difference in incidence of twins in the two stocks. $\overrightarrow{\overrightarrow{0}}$ This difference could lie either in the rate of foetal duplication, or in factors controlling survival in utero, or in both. At either stage the main factors could be genic, and thus amenable to selection, or a matter of heterozygosity or otherwise of the mother, and thus capable of maximization by breeding procedure.

The difference is most easily interpreted as one $\frac{\rho}{3}$ of heterozygosity. Comparison of the genotypes of the mother, from which the observed identicals? came, shows that in Fisher's data these were all $\$$ homozygous, whereas in ours and in Green's data (where, however, the excess of identicals is only N sub-significant) the mothers were mainly heterozygous; in addition, it can be seen that the mutant 0 or normal phenotype of the mother is unimportant. $\omega$ The heterozygous mothers, being the $F_{1}$ of a cross between two closed colonies, were heterozygous foro many unmarked loci as well as the mutant ones, in $\mathbb{D}$ contrast to the homozygous ones; the important? factor may thus be heterosis rather than heterozygosity as such.

Green pointed out that heterozygous females have larger litters than homozygous ones, a situa- $\stackrel{\mathbb{Q}}{\varrho}$ 
tion that holds also in our data. The relation between litter size and twinning rate is likely to be complex. Discrimination between maternal efficiency and within-litter competition, and between primary duplication rate and uterine factors, should, however, be possible with the techniques now available in mice (see McLaren and Michie, 1956). A positive correlation between litter size and twinning rate would favour maternal efficiency as the dominant factor, but our data, though showing that identicals occur in litter sizes, 6,7 , and 8 (Table I), are too small to show a significant trend.

Further experiments along these lines are planned.

The evidence on factors controlling the incidence of the two kinds of twin in man is inconclusive.

It is usually accepted that human monozygotic twinning is heritable. Although there are no clear differences in the frequencies of monozygotics in different populations (Stern, 1960, ch. 25), there are other indications. For example, an appreciable (but insignificant) excess of monozygotics, over the population frequency, was found among the relatives of monozygotics by Greulich (1934) in America. Fisher (1928) found a significant excess of like-sexed twins born to the parents of the fathers of triplets in Great Britain, which he interpreted as showing that monozygotism was more strongly inherited than dizygotism. Slater (1948) found, in England and Wales, a significantly high frequency of twinning in the families of people related to twins, but no difference in this correlation as between like- and unlike-sexed twins; this suggests that both types are equally heritable. Finally, Enders and Stern (1948) found a significant difference between the whites and negroes of America in the trend of increase, with age of mother, of monozygotic twin confinements.

However, opinion varies upon the factors controlling the observed frequencies. Slater concludes 'that the predominant aetiological factors (in twinning of both kinds) are non-genetic'. On the other hand, Enders and Stern 'are inclined to regard the rise in frequency (with age of mother) ... as the expression of a variable in the maternal organism responsible for favouring the occurrence of twinning in developing eggs'. Slater (1953, pp. 5, 3I), quoting his own and others' findings, points out that though the tendency to human twins of both kinds runs in families, each kind of twin tends to be as often related to its own kind as to the other kind: it appears that some common component increases both kinds impartially. This suggests that our findings in mice may be pertinent, for heterozygous mothers have larger litters (corresponding to fraternal twins) and more monozygotics than do homozygous mothers. In conclusion, it seems very likely that both genetic and non-genetic factors are operating in man and in the mouse, but almost any view on their nature and importance can at present be held.

It is of interest to see at what stages of development duplication can occur in the mouse. In man, about one-third of monozygotics are dichorial, and about two-thirds monochorial, of which the commonest have two amnions (Corner, 1955). However, this classification cannot be used to indicate equivalent stages of development in mice, owing to the different origin of the chorion (Bateman, I960). It seems likely that mouse monozygotics will be found to be due to duplication at an early stage. Duplication of the primitive streak has been reported as the effect of the gene $K i$ (Kinky) when homozygous (GluecksohnSchoenheimer, 1949, 1957); but all specimens were inviable, probably due to the late stage at which duplication occurred. The formation of two blastocysts from one egg, argued against by Bateman mainly on the grounds of mechanical difficulties, appears unlikely in view of experimental work by Tarkowski (196I): when two morulae are enclosed in the same artificial zona pellucida, they fuse to form a chimaerical embryo even when they are of opposite sex. This leaves us with a stage at or before implantation, early enough for the twins to have separate yolk sacs and separate placentae. In each pair of Bateman's twins, one member was small and unlikely to survive because it was too far from the mesometrial end of the trophoblast. Since placentation is restricted to this end, viable twins can result only if there are two cell masses lying close to the mesometrial end, or opposite each other but parallel to the uterine axis, or if two egg cylinders arise from one inner cell mass. There is a single case showing that bifurcation of the inner cell mass has occurred: Bodemann (1935) describes two egg cylinders attached to one ectoplacental cone and inside a common yolk sac.

\section{Summary}

The design is given of an experiment to test the occurrence of monozygotic twins in mice, using nine independent chromosome markers and sex.

Data are analysed according to the method given by Stevens (1937), with some expansion, and a significant excess of identical pairs over that expected on a chance basis is found. Monozygotic twinning is estimated to have an incidence 
of about $\mathrm{I}$ in 100 births, with $95 \%$ fiducial limits of 0.2 and $2.6 \%$.

Comparison of the data with those of Fisher and Mather (1936) and Green (1934) indicates that monozygotics have come from heterozygous rather than from homozygous females. The factors controlling these tendencies are discussed in relation to the aetiology of this form of twinning in man.

Current embryological information on mouse twins is scant but the conclusion is reached that duplication resulting in viable twins would have to be of specific kinds occurring at or before implantation.

The experiment was suggested by Sir Ronald Fisher, and the 9 mutants were chosen by $\operatorname{Dr} A$. R. G. Owen of this Department, who also combined the dominants. We are indebted to Dr D. S. Falconer of the Institute of Animal Genetics, Edinburgh, for critical discussion and to $\operatorname{Dr} A$. J. Bateman of the Christie Hospital and Holt Radium Institute, Manchester, for helpful comments, especially on the mechanism of twinning.

One of us (D.A.W.) acknowledges receipt of a D.S.I.R. studentship.

\section{REFERENCES}

Bateman, A. J. (1960). Dichorial one-egg twins in the mouse. Nature (Lond.), $187,339$.

Bodemann, E. (1935). A case of uniovular twins in the mouse. Anat. Rec., 62, 291.

Corner, G. W. (1955). The observed embryology of human singleovum twins and multiple births. Amer. F. Obstet. Gynec., 70, 933.

Enders, T., and Stern, C. (1948). The frequencies of twins, relative to age of mothers, in American populations. Genetics, 33, 263.

Fisher, R. A. (1928). Triplet children in Great Britain and Ireland. Proc. roy. Soc. B, 102, 286.

- and Mather, K. (1936). A linkage test with mice. Ann. Eugen. (Lond.), 7, 303 .

Gluecksohn-Schoenheimer, S. (1949). The effects of a lethal mutation responsible for duplications and twinning in mouse embryos. F. exp Zool., Iro, 47.

- (1957). Trends in mammalian teratology. Pediatrics, 19, 777.

Green, C. V. (1934). Occurrence of uniovular twins in multiple births. Science, 80, 616 .

Greulich, W. W. (1934). Heredity in human twinning. Amer. F. phys. Anthrop., 19, 391.

McLaren, A., and Michie, D. (1956). Studies on the transfer of fertilised mouse eggs to uterine foster-mothers. I. Factors affecting the implantation and survival of native and transferred eggs. F. exp. Biol., 33, 394.

Shields, J. (1962). Monozygotic Twins Brought up Apart and Brought up Together. Oxford University Press, London.

Slater, E. (I948). The inheritance of twinning. Proc. 8 th Int. Congr. Genetics, Lund 1949, Abstr., p. 665.

(1953). Psychotic and Neurotic Illnesses in Twins. Spec. Rep. Ser. med. Res. Coun. (Lond.), 278.

Smith, S. M., and Penrose, L. S. (1955). Monozygotic and dizygotic twin diagnosis. Ann hum. Genet., 19, 273.

Stern, C. (1960). Principles of Human Genetics, 2nd ed. W. H. Freeman, San Francisco and London.

Stevens, W. L. (1937). Significance of grouping [and A test for uniovular twins in mice]. Ann. Eugen. (Lond.), 8, 57, 70.

Tarkowski, A. K. (196I). Mouse chimæras developed from fused eggs. Nature (Lond.), r90, 857.

Wallace, M. E. (1965). The relative homozygosity of inbred lines and closed colonies. $\mathcal{F}$. theor. Biol. In the press.

\section{APPENDIX Analysis of Twinning Data}

If the genotypic class probabilities are unequal, and $\stackrel{\vec{S}}{\vec{S}}$ are given by,

$\mathbf{P}_{\xi}=\frac{I}{n}+\lambda_{\xi}$ for $\xi=I \ldots$, with ${ }_{I}^{n} \lambda_{\xi}=0$ and $\Lambda=\sum_{I}^{n} \lambda^{2} \xi$, then good approximations for increase in expectation and variance are given by $C_{s f} \Lambda$ and $D_{s p} \Lambda$,

where $C_{s f}=\frac{s(s-I)}{2}\left(I-\frac{I}{n}\right)^{s-2}$,

and $D_{s f}=s(s-I)$

$\left\{(n-2)\left(I-\frac{2}{n}\right)^{s-2}+\frac{1}{2}\left(I-\frac{I}{n}\right)^{s-2}-n\left(I-\frac{I}{n}\right)^{2 s-2}\right\}$

(Stevens (1937), \4.2).

It is sufficiently accurate, as the corrections will be small, to calculate $\Lambda$ from the data. If the factors segregate independently, an unbiased consistent estimate of $\Lambda$ is given by

$$
\underset{g=I}{f}\left(\frac{\left(E_{g}{ }^{2}+F_{g}^{2}-A_{g}\right)}{A_{g}\left(A_{g}-I\right)}\right)-\frac{I}{n}
$$

where $E_{g}$ and $F_{g}$ are mutant and normal subtotals of of factor $\mathbf{g}$ for the whole experiment, $\mathbf{E}_{\mathbf{g}}+\mathbf{F}_{\mathbf{g}}=\mathbf{A}_{\mathbf{g}}$, and 0 $\Pi$ denotes the product of all factors yielded by the expression in brackets when $g=I, 2, \ldots f$ (Stevens (I937), \$5.2).

For any factor not suspected of segregating unevenly we replace its component in (I) by 2 .

By a direct extension of Stevens' argument, for a given pair of factors, $\mathrm{g}, \mathrm{h}$ say, not segregating independently, we must replace the product,

$$
\begin{gathered}
\left(\frac{E_{g}{ }^{2}+F_{g}{ }^{2}-A_{g}}{A_{g}\left(A_{g}-I\right)}\right) \times\left(\frac{E_{h}{ }^{2}+F_{h}{ }^{2}-A_{h}}{A_{h}\left(A_{h}-I\right)}\right) \text { in (I) by } \\
\frac{t_{1}{ }^{2}+t_{2}{ }^{2}+t_{3}{ }^{2}+t_{4}{ }^{2}-T}{T(T-I)}
\end{gathered}
$$

where $t_{1}, t_{2}, t_{3}, t_{4}$ are the totals for the four genotypes of $g, h$ for the whole experiment, and $T=t_{1}+t_{2}+t_{3}$ $+t_{4}$. As the $\chi^{2}$ analyses (Tables I and II) give two 0 single factors segregating unevenly, and four pairs of factors segregating non-independently, adjustment $\frac{7}{0}$ is made as follows. These pairs are fortunately disjoint. The estimate of $\Lambda_{c}$ for given set, $c$, of factors, is then $N$ given by

$$
\begin{aligned}
& \Pi_{1}\left(\frac{\mathrm{t}_{1}{ }^{2}+\mathrm{t}_{2}{ }^{2}+\mathrm{t}_{3}{ }^{2}+\mathrm{t}_{4}{ }^{2}-\mathrm{T}}{\mathrm{T}(\mathrm{T}-\mathrm{I})}\right) \times \\
& \Pi_{2}\left(\frac{\mathrm{Eg}{ }^{2}+\mathrm{F}_{\mathrm{g}}{ }^{2}-\mathrm{Ag}_{\mathrm{g}}}{\mathrm{Ag}_{\mathrm{g}}\left(\mathrm{A}_{\mathrm{g}}-\mathrm{I}\right)}\right) \times\left(\frac{1}{2}\right)^{\mathrm{m}}-\frac{\mathrm{I}}{\mathrm{n}}
\end{aligned}
$$

where $\Pi_{1}$ is the product over the significant pairs con- $\stackrel{D}{?}$ tained in $c, \Pi_{2}$ is the product over significant single $\frac{0}{T}$ factors in $c$ not in any of the above pairs, and $m$ is the number of remaining single factors in c segregating $\stackrel{\square}{\triangle}$ evenly and not in any of the above significant pairs. 
If $1_{s f}$ is the number of litters of size s segregating for

$f$ factors, then,

the uncorrected expectation

$$
\begin{aligned}
& =\sum_{s, f} 1_{s f} E_{s f} \\
& =\sum_{s, f} 1_{s f} V_{s f}
\end{aligned}
$$

and the uncorrected variance

and if $1_{s f e}$ is the number of litters of size $s$ segregating for factors of set $c$,

the correction to the expectation $=\sum_{s, f, c} 1_{s f c} C_{s f} \Lambda_{c}$

and the correction to the variance $=\sum_{s, f, c} l_{s f c} D_{s f} \Lambda_{c}$.

On computation, these become:

uncorrected expectation of no. of identities $=4.067$

uncorrected variance $\quad=3.884$

correction for expectation $\quad=0.1 \mathrm{II}$

correction for variance $\quad=0.105$

Therefore : corrected expectation $\quad=4 \cdot 178$ corrected variance $\quad=3.989$ standard deviation $\quad=1.997$

The observed number of identities

$$
=9 \cdot 0
$$

On the hypothesis that there is no monozygotic twinning, the number of identities is distributed approximately normally. With the continuity correction, the observed number is thus significantly excessive at the
I. $52 \%$ level, i.e. there is evidence that twinning has taken place.

There is one significant fourth-order interaction. It concerns loci $T, N, a, b$. If this were to be taken into account, we would replace the relevant expressions in the estimation of $\Lambda$ by

$$
\left(\underset{i}{\Sigma} t_{i}{ }^{2}-\underset{i}{\Sigma} t_{i}\right) /\left\{\sum_{i}^{\Sigma} t_{i}\left(\sum_{i}^{\Sigma} t_{i}-I\right)\right\}
$$

where $t_{i}$ are the 16 genotype class totals for $T, N, a$, and $b$. However, this would increase the corrections to expectation and variance by less than 0.01 and does not therefore affect the above conclusion.

The limits for the frequency of twinning cannot be estimated without knowledge of its distribution, but on the assumption that the number of twins in a sample of our size is distributed approximately normally, with mean and variance $k$, then the $95 \%$ confidence limits for $k$ are given by,

$$
\mathbf{I} \leqslant \mathbf{k} \leqslant \mathbf{I}_{3},
$$

for the 500 mice classified. Thus about half the observed identical pairs were monozygotic, and the frequency of births which were monozygotic is expressible as between the $95 \%$ limits of 0.2 and 2.6 per roo births. 